\title{
A Knowledge-based Design Advisory System for Collaborative Design for MicroManufacturing
}

\author{
X. Dai ${ }^{{ }^{*}}$, Y. Qin ${ }^{1}$ L. Ma ${ }^{2}$ and N. Juster ${ }^{1}$ \\ 1 Design, Manufacture and Engineering Management, University of Strathclyde, Glasgow, G1 1XJ \\ 2 Computer and Information Sciences, University of Strathclyde, Glasgow, G1 1XJ \\ * Corresponding authors: aa5527@coventry.ac.uk
}

\begin{abstract}
The manufacture of micro-products differs from that of conventional products in many ways, not only in the sizes, but also in issues concerning the effects of material properties, tools and manufacturing equipment. There was a need for a new design methodology and associated design tools to aid designers in assessing the design of their micro-products by considering new micro-manufacturing capabilities and constraints. A knowledge-based Design Advisory System (DAS) was, therefore, developed in MASMICRO in which the knowledge-based system with dedicated assessment modules and knowledge representatives based on the ontology was created to implement the distributed design and manufacturing assessment for micro-manufacturing. The modules address the assessment on geometrical features relating to manufacturability, manufacturing processes, selection of materials, tools and machines, as well as manufacturing cost. The Microsoft C\# programming language, ASP.NET web technology, Prolog and Microsoft Access database were used to develop the DAS. The test on the DAS prototype system found to provide an increase of design efficiency due to more efficiently using design and manufacturing knowledge and affording a web-based collaborative design environment.
\end{abstract}

Keywords: Micro-manufacturing, Knowledge-based System, Design Advisory System, Micro-product Design. 


\section{Introduction}

A main aim of the MASMICRO project was to develop manufacturing facilities to support new micro-manufacturing activities [1]. The equipment developed expands/increases the capabilities of micro-manufacturing which further creates new opportunities for product innovation. To support product development with the MASMICRO manufacturing facilities, a product design assessment system has been developed, which not only applies the manufacturing constraints to the design to ensure that the design is feasible for micromanufacturing, but also provides new manufacturing knowldge to support product design innovation by taking full advantage of newly-increased manufacturing capabilities in micromanufacturing.

Some Knowledge-Based Decision Support Systems (KBDS) have been developed for assisting in improving desing and manufacture. However, most of these are concerned with macro-manufacturing, with only a few of them considering micro-manufacturing. Furthermore, most of these systems are based on the use of standalone PCs rather than being web-based, which is not convenient for clients working within a collaborative environment. For example, a knowledge-based expert system at the discretion of casting-product designers was employed as a real-time expert advisor to assist product designers to achieve the correct casting design and appreciate process selection for a given component [2]. A KBDS for metal-forming was developed [3] which was capable of generating feasible process plans for various sheet and bulk-metal forming modules. A knowledge-based framework for the design of progressive dies was also developed [4] to support metal stamping, etc.

Some of the previously created knowledge-based design systems demonstrated the capability of collaborative design for discrete organizations through the Internet. Using Internet technology, the model and knowledge-source of design in the systems can be dynamically accessed, shared and undated in the web environment by authorised remotely-located users. Therefore, more efficient design cooperation, product pre-review and assessment can be implemented. For example, a web-based knowledge system architecture was proposed for collaborative product-evelopment [5]. A web-based knowledge-intensive collaborative design 
system called WebKIDSS was also presented [6]. The latter system was implemented using the concurrent integration of multiple cooperative knowledge-sources and Java/Java Bean and CORBA technologies. The system was applied to injection moulded products. A process planning optimization module was also introduced [7], which was wrapped as a web-enabled service and deployed in the Internet to support distributed design and manufacturing systems. In this development, VRML/XML and Java technologies were utilised.

The above-introduced systems were, however, not related to applications to design for micromanufacture, especially design for micro-forming. In the research and development presented in this paper, the prototype of a knowledge-based Design Advisory System (DAS) was developed for collaborative design for micro-manufacturing, as part of the MASMICRO project's planned tasks. The DAS consists of various assessment modules, including that for product-geometry features relating to manufacturability, manufacturing processes, selection of materials, tools and manufacturing machines, as well as manufacturing cost. The users can import a CAD design model to the DAS using its User Interface (UI), which is similar to a web page with dialog boxes. The users can also add, edit and delete (under authorization) the design parameters of the micro-products in the database of the DAS, the database having been designed and programmed using Microsoft C\# [8], the ASP.Net [9] web technique and Microsoft Access [10] (or Microsoft SQL Server). Designers or users are able to use the DAS to obtain an effective solution within a knowledge web-based collaborative environment.

\section{Methodology of Design Assessment for Micro-Manufacturing}

\subsection{The products and processes addressed in the DAS}

After examining micro-manufacturing processes involved in the Masmicro project, three common types of the micro-formed products were decided to be considered in the first prototype of the DAS:

(a) Bulk parts, which are, mostly, axially-symmetrical or rotationally--symmetrical, such as micro-pins, micro-shafts and gears;

(b) Sheet parts with various thicknesses and flat geometries, or 2.5D parts with raised/lowered profiles, such as micro-switch parts, micro-caps and micro-connector parts; 
(c) Cans/tubes, which may have local 3D features, formed from initially cylindrical bars or tubes, such as micro-camera shafts and micro-fluidic-device parts.

The preliminarily applicable processes used in the DAS for micro-manufacturing process assessment are: micro-extrusion, micro-stamping, micro-hydro-forming, micro-EDM and micro-laser-forming.

\subsection{Design considerations for developing the DAS}

Design of a micro product should simultaneously investigate the product concepts and the product-manufacturing feasibility. This will eventually result in a decision regarding the preferred manufacturing methods, tools and machines. Referring to the micro-manufacturing, the following major factors will have to be considered during product design: overall dimensions of the micro-parts/products, local features of the part/eomponent, manufacturing shape capability, tolerance and surface quality capability, material capability, material properties of the part/component after processing, characteristics of mass-production, manufacturing cost, and synthesis factors. These were taken into account in the design of the DAS.

\subsection{Knowledge-based collaborative environment for developing the DAS}

At the earlier stage of the project, a stand-alone DAS was developed to support the design assessment of a micro-product, where the issues of concern included the selection of the manufacture process and the material, and the decisions regarding the cost of the tool, of the machine and of manufacture. In this situation, the DAS could only use personal PCs and could not provide a collaborative design environment to many partners of the project: the application of the DAS was therefore constrained. After close collaboration with the partners of the project, a knowledge-based collaborative DAS was proposed and created, which is web-based and which the project partners and potential end-users (under authorization) can access and use.

As illustrated in Fig 1, the knowledge-based DAS was designed in an interactive mode, in which the user can not only access the user interface of the DAS through the Internet, but can 
also modify and update the design data in the database of the DAS. Here, a server that is based on the web protocol is used as the service provider or browser of the web-based DAS. The information and design knowledge can be searched and shared by all of the users who can access the DAS through the Internet.

\subsection{Methods for knowledge representation}

In order to effectively and accurately utilize the knowledge resources in the DAS, it is necessary to classify the knowledge into different categories. Two methods, i.e. production rules and frames [11], have been adopted in the DAS to represent knowledge. The former, production rules, associates with the product specifications, design evaluation and product technological data and experience/practice. Based on the architecture presented in the Fig 1, the product specifications and design evaluation can be built in the KBDS of the DAS and they function as the evaluation principles and control methods. The technological data can be stored in the database of the DAS, which can be searched by the users through the Internet. The latter, frames, which include the previous empirical data and methods, can be represented by a logical-decision type method such as "If - Then” in the Inference Engine or assessment modules of the DAS.

\section{Design of the Design Advisory System}

\subsection{Architecture of the DAS}

After examining the issues concerning the methodology of design assessment for micromanufacturing, the architecture of the knowledge-based collaborative Design Advisory System was built up (presented in the Fig 1). Generally, the DAS includes four parts, as shown in Fig 2 - the User Interface (UI), the Inference Engine, the Database and KBDS, and their functions being briefed below:

User Interface (UI): The UI of the DAS, created with Microsoft Visual Studio.Net 2003 Compiler, Microsoft C\# language and the ASP.Net web technique, provides an easy access for the users to use the DAS through the Internet. The UI is designed to connect with the 
Inference Engine (for User-Machine dialog and data input/output), CAD drawings, the KBDS and the database. The DAS can run in a specified service server and provide a web-based collaborative environment where the authorized user can browse, add and modify the necessary data in the database of the DAS through the interactive dialog box in the UI, including both text and graphic illustrations.

Inference Engine: the Inference Engine involves and realises the control strategy for the assessment of the design of the micro-product. It was arranged to have forward and backward chaining mechanisms. In this way, the micro-product design parameters provided by the user could be judged as whether acceptable or not using the stored design rules and empirical data in the KBDS or the data-base. The Inference Engine was designed using Microsoft C\#, ASP.Net and Prolog.

Knowledge-Based Decision System (KBDS): the KBDS contains logical objects, facts and goals, as well as the system of rules (specifications) representing the relationships between them. Microsoft C\# and Microsoft Access (SQL Server were used to design the KBDS.

Database: combining with the Knowledge-Based Decision System (KBDS), the database is an independent part of the DAS, which contains materials properties, technological parameters, tool parameters and forming-machine parameters. This data presents, practically, the appropriate facts for the system. The Microsoft Access (SQL Server) was used for the design of the database.

\subsection{Functions of the DAS}

The prototype of the DAS was developed with referrence to the architecture of both knowledge-based and web-based DAS. In order to be able to assess the manufacturability of the micro-product that the users has developed in an easy and flexible way, functionalassessment modules were created in the UI of the DAS, the design and arrangement of these modules being shown in Fig 3. The assessment functions of these assessment modules include the following aspects: product geometry features, manufacturing process selection, material applicability, selection of tools and machines, and manufacturing cost. 
To assess a micro-product, as shown in Fig 3, firstly, the users can input and upload his/her CAD model or drawing using the click button "CAD drawing input”. The CAD model or drawing, is then displayed in the image frame of the UI of the DAS. For a general assessment of a user's product design, the assessment module "Product Overview" can be employed, the user simply following the assessment procedures as specified in the assessment modules:
(a). Check product type.
(b). Check product geometrical features.
(c). Check process capability.
(d). Check tolerance and surface-quality capability.
(e). Check tool and machine capability.
(f). Decide preliminary process planning.
(g). Assess the manufacturing cost.

If the user wish to assess his/her design of the product in respect of other issues, further relevant assessment modules can be used. The key reqirement is that the assessment procedures in a assessment module need to be followed rigorously. For example, in the Material Assessment Module, the users can search and select the proper material type from the database, based on different material standards, and then, follow the assessment procedure to judge whether their selected material is suitable for a specific, proposed manufacturing process which has been included in the DAS. For any process which has not been covered in the system, the user may have to use his/her own experience/knowledge to assist in the design assessment. However, the system is developed with an open architecture which allows the user to add data and knowledge to the corresponding database and knowledge base, even add new assessment modules for further development.

\section{System Testing and Validation}

To illustrate the funcitons of the prototype DAS, a sample component, a micro-pin, and the assessment module "Product Overview" are selected, as shown in Fig 3. In the following UI or web page of the assessment module, the user can check and select the product type from the product drop-down list. For instance, after the micro-pin has been selected, the "Enter" button should be clicked, upon which the next UI or web page will appear as shown in Fig 4, 
whereupon the assessment module will then assess the micro-pin product step-by-step, following the assessment procedure.

Before using an assessment module, the user should analyse the design and then decide upon the main geometrical features and attributes of the micro-product. For the example component, the micro pin, the location and number of holes, bosses and transitions, as shown in Fig 4, should be examined. Then the user should enter the number and parameters of the holes, bosses and transitions in the designated dialog boxes. The assessment module enables the separate assessment of each feature listed in the drawing and checks the suitability of the design. Similarly, the user can employ a dialog box to define his/her product design specifications, such as the tolerance, surface quality and material requirements, overall sizes, difficult features, etc, and the assessment module will then automatically check and assess the compatibility/manufacturability of these parameters with use of the KBDS/database in the DAS. The assessment results can be displayed automatically in the output dialog boxes, as shown in Fig 5, to advise the user as to whether or not his/her design is acceptable.

\section{Conclusions and Further Considerations}

The paper presents a prototype knowledge-based collaborative Design Advisory System with various assessment modules for micro-manufacturing (mainly to support uses of the manufacturing facilities developed within the MASMICRO project). The test results obtained with the prototype show an improvement in design efficiency, in terms of easier utilisation of knowledge, and indicate the potential for greater employment of the web-based collaborative design environment to support design for micro-manufacturing.

The knowledge-based collaborative DAS is used herein for the first time of application to design for micro-forming. It is shown that such application is able to secure significant benefits, including the enhancement of right-time micro-product design, reasonable process decisions, less reliance on design expertise, etc. Furthermore, the DAS can also be expanded to applications involving other manufacturing processes than that addressed in the MASMICRO project. 


\section{Acknowledgements}

The authors would like to thank the following: the EC for funding this research - part of the EU FP6 MASMICRO Project (www.masmicro.net); the University of Strathclyde for the provision of research facilities; and partners in the MASMICRO Project for contributions to the development of the design and manufacturing knowledge used in the DAS.

\section{References}

[1] Y. Qin, "Micro-forming and miniature manufacturing systems - Development needs and perspectives”, Keynote Paper (plenary address) of the $11^{\text {th }}$ Int. Conf. of Metal Forming, Sept. 2006, Journal of Materials Processing Technology, Vol. 177, No. 1-3, 2006, pp. 8-18.

[2] A. Er, R. Dias, “A rule-based expert system approach to process selection for cast components”, Knowledge-Based Systems, 13 (2000) 225-234.

[3] M. Tisza, "Expert systems for metal forming”, Journal of Materials Processing Technology, 53 (1995) 423-432.

[4] B. T. Cheok, A. Y. C. Nee, "Trends and developments in the automation of design and manufacture of tools for metal stampings”, Journal of Materials Processing Technology, 75 (1998) 240-252.

[5] K. Rodriguez, A. Al-Ashaab, "Knowledge web-based system architecture for collaborative product development”, Computer in Industry 56(2005) 125-140.

[6] X. F. Zha, H. Du, "Knowledge-intensive collaborative design modeling and support Part II: System implementation and application”, Computer in Industry 57_(2006) pp. 56-71.

[7] W. D. Li, “A Web-based service for distributed process planning optimization”, Computer in Industry, 56 (2005) 272-288

[8] J. Foxall, in: SAMS Teach Yourself Microsoft Visual C\#. NET 2003 in 24 Hours, edited by C. Hall, Publications/SAMS Publishing, Second edn., Indianapolis, Indiana, USA (2004) 
[9] G. A. Duthie, in: Microsoft asp.net programming with microsoft visual c\#.net step by step, edited by A. Hamilton, Publications/Microsoft Press, Redmond, Washington (2003).

[10] A. Blanton, in: Microsoft Office Access 2003 Step by Step, edited by A. Blanton, Publications/ Microsoft Press, Redmond, Washington (2004).

[11] W. M. Sing and K. P. Rao, "Knowledge-based process layout system for axisymmetrical deep drawing using decision tables”, Computers ind. Engng, Vol. 32, No.2, (1997) 299-319

\section{List of the Captions of the Figures}

Fig. 1 Knowledge collaborative-architecture of the Design Advisory System

Fig 2 Simplified architecture of the Design Advisory System

Fig 3 The User-Interface of the Design Advisory System

Fig 4 Assessment of the design of the micro-pin component

Fig 5 Results of a preliminary processing plan and interface for estimation of the manufacturing cost 


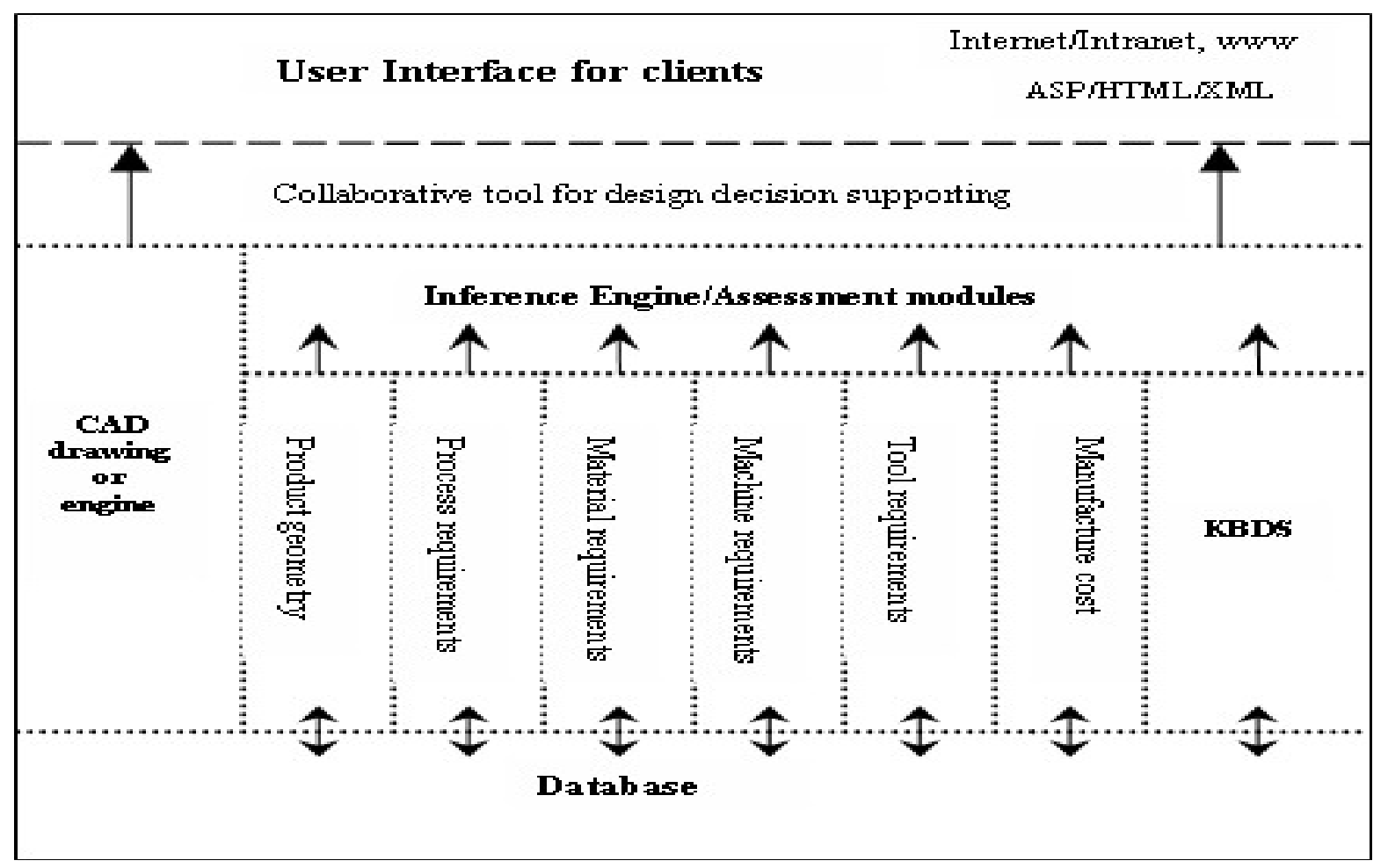

Fig. 1 Knowledge collaborative-architecture of the Design Advisory System 


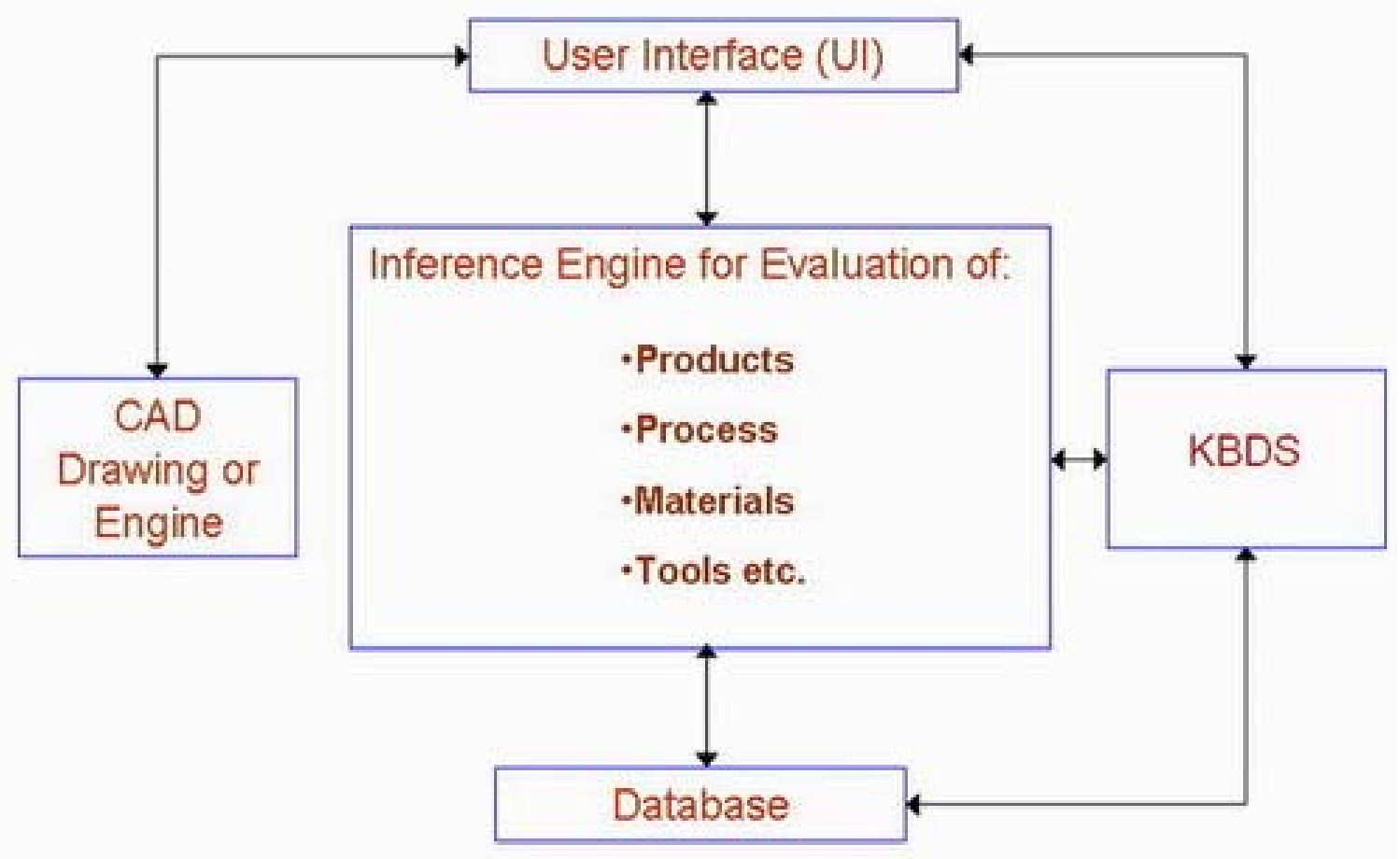

Fig 2 Simplified architecture of the Design Advisory System 


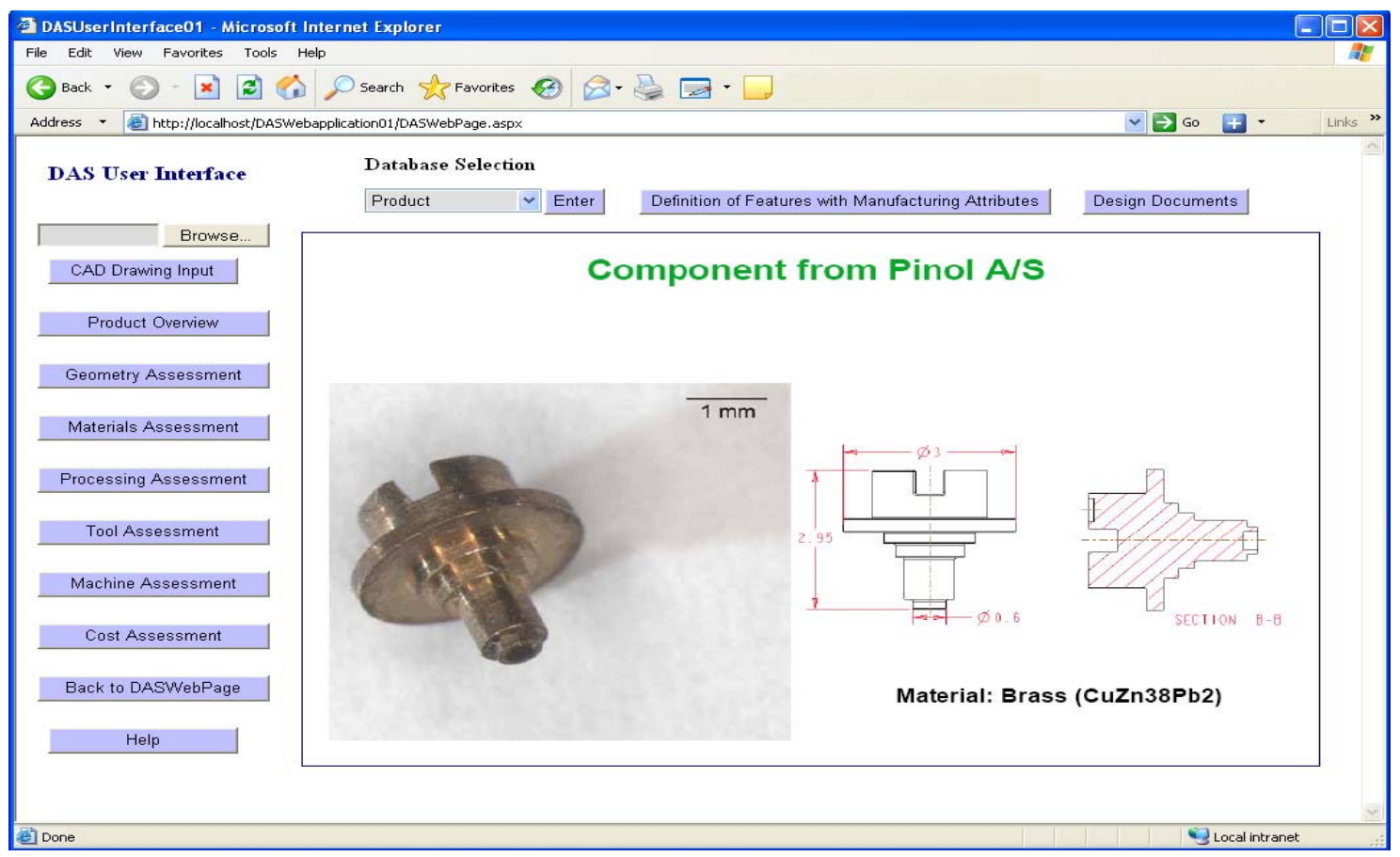

Fig 3 The User-Interface of the Design Advisory System 


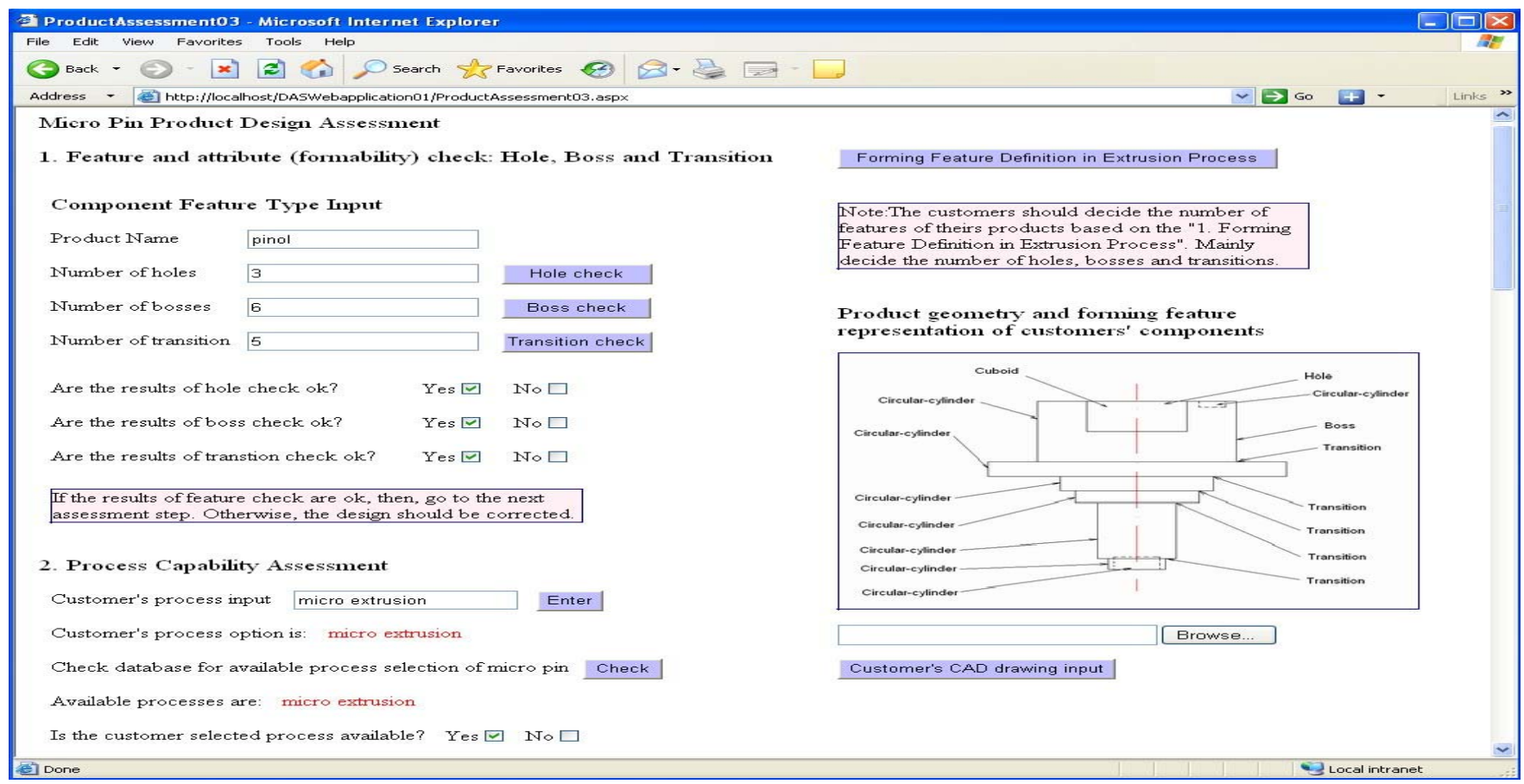

Fig 4 Assessment of the design of the micro-pin component 


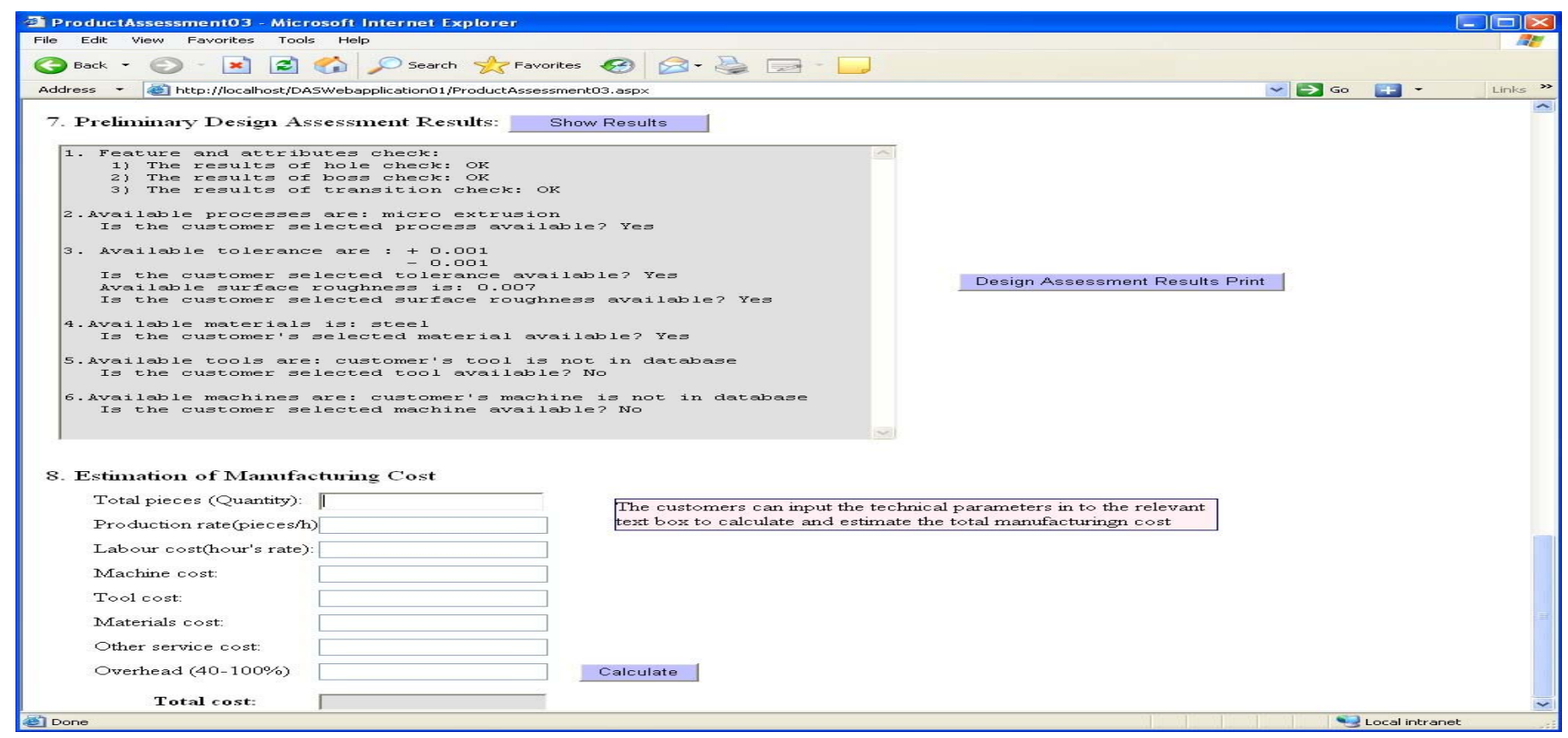

Fig 5 Results of a preliminary processing plan and interface for estimation of the manufacturing cost 